\title{
Changes in Price for Generic Drugs in the USA, 2008-2016
}

\author{
Chintan V. Dave, PharmD, PhD, Gregory Brill, MS, and Aaron S. Kesselheim, MD, JD, MPH
}

Check for updates

Program On Regulation, Therapeutics, And Law (PORTAL), Division of Pharmacoepidemiology and Pharmacoeconomics, Brigham and Women's Hospital, Boston, MA, USA.

J Gen Intern Med 34(9):1677-9

(c) Society of General Internal Medicine 2019
DOI: $10.1007 / \mathrm{s} 11606-019-05033-3$

prescription frequency groups, with the high tercile corresponding to the most commonly prescribed drugs.

\section{RESULTS}

$\mathrm{W}$ idespread use of low-cost generic drugs has improved patient adherence and clinical outcomes while reducing health care spending. However, some generic drug prices have risen due to insufficient competition levels, ${ }^{1,2}$ and drug shortages, ${ }^{3}$ which threatens to undermine these benefits. ${ }^{4}$ To characterize the recent trends in the US generic-drug marketplace, we sought to examine price changes for generic drugs between 2008 and 2016.

\section{METHODS}

The pharmacy files from Truven MarketScan Commercial Claims and Encounters Database-comprised of deidentified insurance claims sourced from 130 commercial employer-based health plans covering 30 million annual lives - for years 2008-2016 were utilized to identify a cohort of drugs available as generics throughout the 9-year period. The total price/unit associated with a generic drug dispensing was estimated by summing the patient and third-party components, and dividing by quantity supplied. The 9-year study period was divided into 18 intervals of 6 months. Prices were estimated for each generic drug in every period, with the first half of 2008 as the baseline.

Percentage changes in drug prices from their baseline were estimated for the study-drugs in every period; categories of price change ratios were calculated by dividing the price in each period by the baseline value. Subgroup analysis included stratification per baseline prescription frequency, a representation of market size. Baseline prescribing frequency was estimated by dividing the number of study-drug dispensings by total dispensings in the baseline period. Study drugs were grouped into three
Within the overall cohort of 1099 generic drugs, mean prices increased by $39.9 \%$ (95\% CI, 25.7-54.3) from their 2008 levels, with most of this increase occurring during or after 2012 (Fig. 1; $p<0.001$ for trend). By contrast, median prices fell $30.0 \%$ (interquartile range [IQR], -60.5 to 40.1 ). Prices for $189(17.2 \%)$ drugs more than doubled, and for $112(10.1 \%)$ more than tripled; 711 (64.6\%) drug prices decrease during this period, and for 668 (60.8\%) drugs, this decrease was by more than $10 \%$.

The mean drug price changes in the low-, middle-, and high-prescription frequency groups were $91.5 \%$ (95\% CI, 61.2-121.8; $p<0.001$ for trend), $42.6 \%$ (95\% CI, 17.8-67.4; $p<0.001$ for trend), and $-14.2 \%(95 \% \mathrm{CI},-30.1$ to $1.7 ; p=$ 0.48 for trend), while the median changes in price were $-9.4 \%$ (IQR, -44.1 to 97.7 ), $-25.0 \%$ (IQR, -55.4 to 51.0 ), and $54.3 \%$ (IQR, -71.0 to -17.9 ). Ninety $(24.6 \%)$ drugs in the low-prescription frequency group had prices more than double compared with $28(7.7 \%)$ in the high-prescription frequency group. Prices for 293 (80.0\%) drugs in the high-prescription frequency group decreased, and for $283(77.3 \%)$ this decrease was for more than $10 \%$.

\section{DISCUSSION}

Between 2008 and 2016 in a cohort of 1099 generic drugs, prices for 189 (17.2\%) drugs more than doubled, while 668 (60.8\%) drugs experienced a price decrease (Table 1). Deflationary pressures on the generic drug market including recent consolidations within the system for the distribution and financing of prescription drugs may explain why prices for most drugs decreased during this period. ${ }^{5}$ Decreases in generic drug prices occurred among the most commonly used products, signaling a favorable net effect for patients and overall health

Published online May 7, 2019 


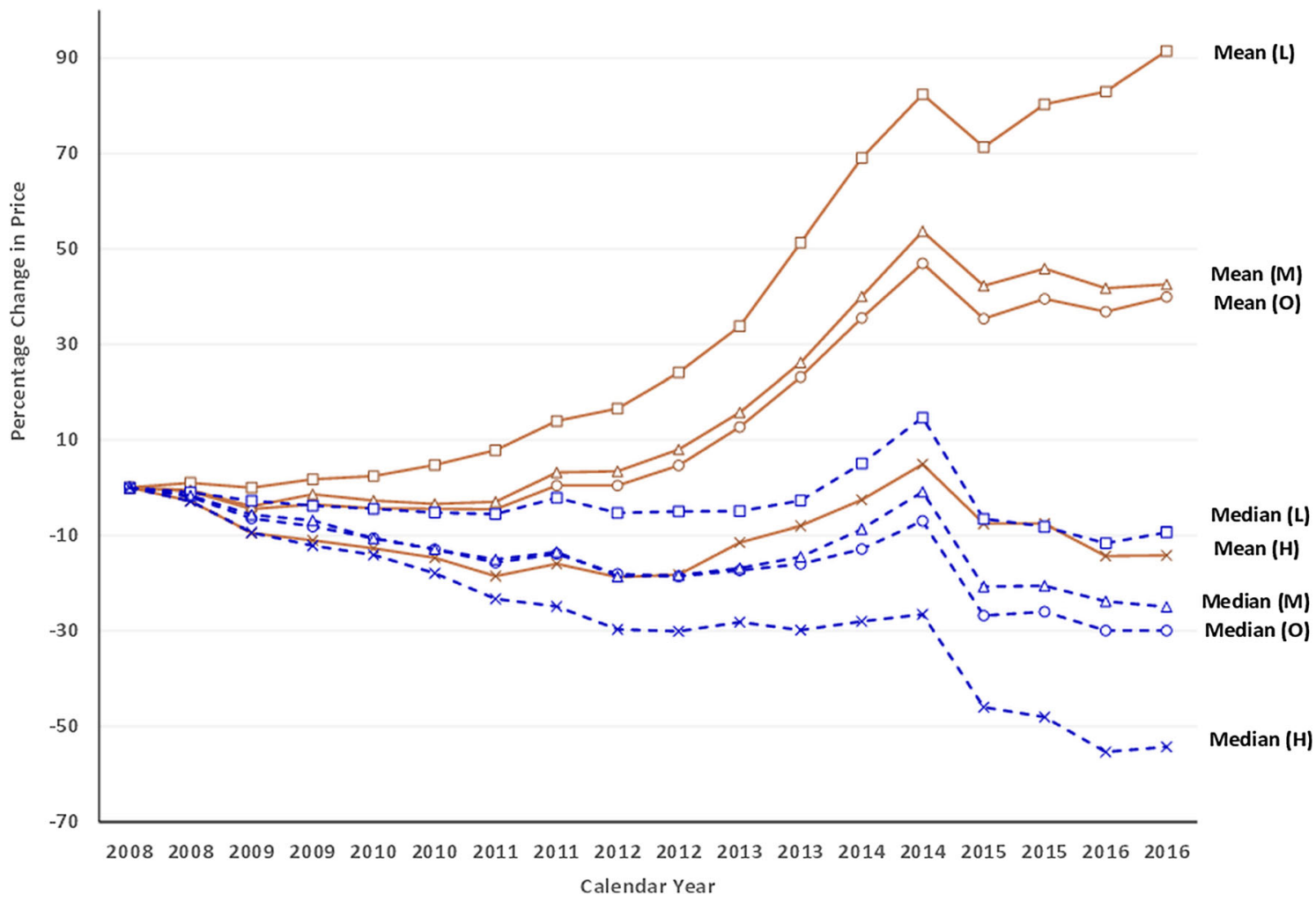

Figure 1 Mean and median percentage change in generic drug prices, 2008-2016 for the overall cohort of generic drugs, and within terciles of prescribing frequency. Drug prices were estimated for 1099 generic drugs for the 14 study periods (not adjusted for inflation). Prices estimated in the first half of 2008 were used as reference. Baseline prescribing frequency was estimated by dividing the number of study-drug dispensings by the total number of dispensings in the baseline period; using terciles, study drugs were grouped into three prescription frequency groups, with the highest tercile corresponding to the most commonly prescribed drugs. The red line represents the mean change in prices and the blue median. The lowest-, middle-, and highest-prescribing frequency groups are represented by $(\mathrm{L}),(\mathrm{M})$, and $(\mathrm{H})$ respectively, while the overall cohort is represented with $(\mathrm{O})$.

care spending. However, our findings may not be generalizable to drugs that became generic after 2008 .

By contrast, we identified a higher prevalence of price spikes among infrequently prescribed generic drugs. The increasing divergence between the mean and median changes in drug prices after 2011 suggests greater price spikes among this small cadre of generic drugs during the final years of our study. Policy solutions should seek to stabilize prices for these drugs without affecting effective competition that helps keep costs low among the majority of generic drugs.

Corresponding Author: Chintan V. Dave, PharmD, PhD; Program On Regulation, Therapeutics, And Law (PORTAL), Division of Pharmacoepidemiology and Pharmacoeconomics Brigham and Women's Hospital, Boston, MA, USA (e-mail: chintandave19@gmail. com).

Author Contributions Dr. Dave had full access to all the data in the study and takes responsibility for the integrity of the data and the accuracy of the data analysis.
Study concept and design: Dave, Kesselheim.

Acquisition, analysis, or interpretation of data: All authors. Drafting of the manuscript: Dave.

Critical revision of the manuscript for important intellectual content: All authors.

Statistical analysis: Dave, Brill.

Administrative, technical, or material support: Kesselheim.

Study supervision: Kesselheim.

Funding/Support The study is funded by Arnold Ventures. Dr. Kesselheim also receives research grant support from the Engelberg Foundation, and the Harvard-MIT Center for Regulatory Science.

\section{Compliance with Ethical Standards:}

Conflict of Interest: The authors declare that they do not have a conflict of interest.

Role of the Funder/Sponsor: The funders had no role in the study design, data collection and analysis, decision to publish, or preparation of the manuscript. 
Table 1 Price Changes in the Cohort of Generic Drugs for Calendar Periods 2008-2016

\begin{tabular}{|c|c|c|c|c|c|}
\hline Calendar time & $2008^{*}$ & $2010^{*}$ & $2012^{*}$ & $2014^{*}$ & 2016 \\
\hline \multicolumn{6}{|c|}{ Price ratio group, $n(\%)^{\dagger}$} \\
\hline \multicolumn{6}{|l|}{ Overall $(N=1099)$} \\
\hline Increased in price & 307 (27.9) & $251(22.8)$ & 315 (28.6) & $491(44.6)$ & $388(35.3)$ \\
\hline $1 \leq \mathrm{ref}<1.10$ & $242(22.0)$ & $103(9.4)$ & $67(6.1)$ & $46(4.2)$ & $33(3.0)$ \\
\hline $1.10 \leq \mathrm{ref}<2$ & $62(5.6)$ & $116(10.5)$ & $163(14.8)$ & $264(24.0)$ & $166(15.1)$ \\
\hline $2 \leq \mathrm{ref}<3$ & $2(0.2)$ & $19(1.7)$ & $42(3.8)$ & $80(7.3)$ & $77(7.0)$ \\
\hline$\geq \overline{3}$ ref & $1(0.1)$ & $13(1.2)$ & $43(3.9)$ & $101(9.2)$ & $112(10.1)$ \\
\hline Decreased in price & $792(72.0)$ & $848(77.1)$ & $784(71.3)$ & $608(55.3)$ & 711 (64.6) \\
\hline $0.90<\operatorname{ref}<1$ & $707(64.3)$ & $211(19.1)$ & $102(9.3)$ & $83(7.5)$ & $43(3.9)$ \\
\hline $0.50<\operatorname{ref} \leq 0.90$ & $84(7.6)$ & $606(55.1)$ & $571(51.9)$ & $393(35.7)$ & $273(24.8)$ \\
\hline $0.33<\operatorname{ref} \leq 0.5$ & $1(0.1)$ & $30(2.7)$ & $82(7.5)$ & $93(8.5)$ & $196(17.8)$ \\
\hline$\leq 0.33 \mathrm{ref}$ & $0(0.0)$ & $1(0.1)$ & $29(2.6)$ & $39(3.5)$ & 199 (18.1) \\
\hline \multicolumn{6}{|c|}{ Lowest prescription frequency group $(n=366)^{*}$} \\
\hline Increased in price & $155(42.3)$ & $145(39.6)$ & $163(44.5)$ & $207(56.5)$ & 167 (45.6) \\
\hline $1 \leq \operatorname{ref}<1.10$ & $116(31.6)$ & $66(18.0)$ & $32(8.7)$ & $15(4.1)$ & $10(2.7)$ \\
\hline $1 . \overline{1} 0 \leq \mathrm{ref}<2$ & $38(10.3)$ & 61 (16.6) & $90(24.5)$ & $108(29.5)$ & $67(18.3)$ \\
\hline $2 \leq \mathrm{ref}<3$ & $1(0.3)$ & $12(3.3)$ & $20(5.5)$ & $37(10.1)$ & $34(9.3)$ \\
\hline$>3$ ref & $0(0.0)$ & $6(1.6)$ & $21(5.7)$ & $47(12.8)$ & $56(15.3)$ \\
\hline Decreased in price & $211(57.6)$ & $221(60.3)$ & $203(55.4)$ & $159(43.4)$ & $199(54.3)$ \\
\hline $0.90<\operatorname{ref}<1$ & $175(47.8)$ & $78(21.3)$ & $44(12.0)$ & $28(7.7)$ & $18(4.9)$ \\
\hline $0.50<\operatorname{ref} \leq 0.90$ & $35(9.6)$ & $136(37.1)$ & $136(37.1)$ & $102(27.8)$ & $106(28.9)$ \\
\hline $0.33<\operatorname{ref} \leq 0.5$ & $1(0.3)$ & $7(1.9)$ & $18(4.9)$ & $19(5.2)$ & $36(9.8)$ \\
\hline$\leq 0.33 \mathrm{ref}$ & $0(0.0)$ & $0(0.0)$ & $5(1.4)$ & $10(2.7)$ & 39 (10.6) \\
\hline \multicolumn{6}{|c|}{ Middle prescription frequency group $(n=367)$} \\
\hline Increased in price & $105(28.6)$ & $74(20.2)$ & $101(27.5)$ & $180(49.1)$ & $148(40.4)$ \\
\hline $1 \leq \mathrm{ref}<1.10$ & $84(22.9)$ & $29(7.9)$ & $21(5.7)$ & $20(5.5)$ & $9(2.5)$ \\
\hline $1 . \overline{1} 0 \leq \mathrm{ref}<2$ & $20(5.5)$ & $36(9.8)$ & $51(13.9)$ & $92(25.1)$ & $68(18.5)$ \\
\hline $2 \leq \mathrm{ref}<3$ & $1(0.3)$ & $5(1.4)$ & $14(3.8)$ & $31(8.5)$ & $35(9.6)$ \\
\hline$\geq \overline{3}$ ref & $0(0.0)$ & $4(1.1)$ & $15(4.1)$ & $37(10.1)$ & $36(9.8)$ \\
\hline Decreased in price & $262(71.5)$ & $293(80.0)$ & $266(72.6)$ & $187(51.0)$ & $219(59.8)$ \\
\hline $0.90<\mathrm{ref}<1$ & $244(66.6)$ & $77(21.0)$ & $36(9.8)$ & $30(8.2)$ & $11(3.0)$ \\
\hline $0.50<\operatorname{ref} \leq 0.90$ & $18(4.9)$ & $211(57.6)$ & $209(57.1)$ & $134(36.6)$ & $96(26.2)$ \\
\hline $0.33<\operatorname{ref} \leq 0.5$ & $0(0.0)$ & $4(1.1)$ & $16(4.4)$ & $16(4.37)$ & $70(19.1)$ \\
\hline & & $1(0.3)$ & $5(1.4)$ & $7(1.91)$ & 42 (11.4) \\
\hline \multicolumn{6}{|c|}{ Highest prescription frequency group $(n=366)^{\ddagger}$} \\
\hline Increased in price & $47(12.8)$ & $32(8.74)$ & $51(13.9)$ & $104(28.4)$ & $73(19.9)$ \\
\hline $1 \leq \mathrm{ref}<1.10$ & 42 (11.4) & $8(2.2)$ & $14(3.8)$ & $11(3.0)$ & $14(3.8)$ \\
\hline $1.10<\operatorname{ref}<2$ & $4(1.09)$ & $19(5.2)$ & $22(6.0)$ & $64(17.4)$ & $31(8.5)$ \\
\hline $2 \leq \mathrm{ref}<3$ & $0(0.0)$ & $2(0.5)$ & $8(2.2)$ & $12(3.23)$ & $8(2.2)$ \\
\hline$\geq \overline{3}$ ref & $1(0.3)$ & $3(0.8)$ & $7(1.9)$ & $17(4.6)$ & $20(5.5)$ \\
\hline Decreased in price & $319(87.1)$ & $334(91.2)$ & $315(86.0)$ & $262(71.5)$ & $293(80.0)$ \\
\hline $0.90<\operatorname{ref}<1$ & 288 (78.6) & $56(15.3)$ & $22(6.0)$ & $25(6.8)$ & $14(3.8)$ \\
\hline $0.50<\operatorname{ref} \leq 0.90$ & $31(8.4)$ & $259(70.7)$ & $226(61.7)$ & $157(42.8)$ & $71(19.3)$ \\
\hline $0.33<\operatorname{ref} \leq 0.5$ & $0(0.0)$ & $19(5.2)$ & $48(13.1)$ & $58(15.8)$ & $90(24.5)$ \\
\hline$\leq 0.33 \mathrm{ref}$ & $0(0.0)$ & $0(0.0)$ & $19(5.2)$ & $22(6.0)$ & $118(32.2)$ \\
\hline
\end{tabular}

Drug-specific price ratios were estimated using prices from the first half of 2008 as reference; the cohort was comprised of 1099 generic drugs *Data for second half of the calendar year are presented

${ }^{+}$Categories of price change ratios were calculated by dividing the price of a drug in each period by their reference (baseline) value estimated in the first half of 2008

${ }^{7}$ Baseline prescribing frequency was estimated by dividing the number of study-drug dispensings by the total number of dispensings in the baseline period; using terciles, study drugs were grouped into three prescription frequency groups, with the highest tercile corresponding to the most commonly prescribed drugs

\section{REFERENCES}

1. Dave CV, Hartzema A, Kesselheim AS. Prices of generic drugs associated with numbers of manufacturers. N Engl J Med. 2017;377(26):2597-2598.

2. Dave CV, Kesselheim AS, Fox ER, Qiu P, Hartzema A. High Generic drug prices and market competition: a retrospective cohort study. Ann Intern Med. 2017;167(3):145-151.

3. Dave CV, Pawar A, Fox ER, Brill G, Kesselheim AS. Predictors of Drug shortages and association with generic drug prices: a retrospective cohort study. Value Health. 2018;21(11):1286-1290.
4. Kesselheim AS, Avorn J, Sarpatwari A. The high cost of prescription drugs in the United States: origins and prospects for reform. JAMA. 2016;316(8):858-871.

5. Dabora MC, Turaga N, Schulman KA. Financing and distribution of pharmaceuticals in the United States. JAMA. 2017;318(1):21-22.

Publisher's Note Springer Nature remains neutral with regard to jurisdictional claims in published maps and institutional affiliations. 